\title{
Determining the Relationship between Academic Self-efficacy and Student Engagement by Meta- analysis
}

\author{
Dian-Fu Chang \\ Graduate Institute of Educational Policy and Leadership, \\ Tamkang University \\ New Taipei City, Taiwan \\ 140626@mail.tku.edu.tw
}

\author{
Wei-Cheng Chien \\ Department of Education, \\ National Chengchi University, \\ Taipei City, Taiwan \\ magi52042@gmail.com
}

\begin{abstract}
Academic self-efficacy has become an important factor that will affect students' choices of their learning task and behaviors, as well as their mentality and emotions on learning. Moreover, student engagement has been found playing a key to success in learning. This study tried to analyze the relationship between academic self-efficacy and student engagement through meta-analysis. Meta-analysis is the statistical procedure for combining data from series of studies focused on specific topics. When the effect varies from one study to the next, meta-analysis may be used to identify the variation. To determine their relationship, we selected 26 previous studies from 1990 to 2014 in the target data banks and conducted by Comprehensive Metaanalysis (CMA). The results reveal: (1) There is a relationship existedbetween academic self-efficacy and student engagement; (2) In different school level, that only shows the moderating effect on academic self-efficacy and behavioral engagement.
\end{abstract}

Keywords-Meta-analysis; academic self-efficacy; student engagement; self-efficacy

\section{INTRODUCTION}

Academic self-efficacy expectations are a student's beliefs in their ability to perform the necessary behaviors to produce a certain outcome. Academic self-efficacy has become an important factor that will affect students' choices of their learning task and behaviors, as well as their mentality and emotions on learning. Moreover, student engagement has been found playing a key to success in learning in previous studies. The objective of this study was to examine the correlation between students' academic self-efficacy and student engagement. In addition, we considered whether this relationship is affected by education levels. Given this purpose, this study addressed the following questions: (a) What are the results of a meta-analysis of the correlation between academic self-efficacy and student engagement? (b) Is there a difference in the relationship between student's academic self-efficacy and engagement at different levels of education?

\section{LITERATURE REVIEW}

Self-efficacy refers to individuals' beliefs in their ability to produce desired results[1].The self-efficacy component of Bandura's social-cognitive theory has had a profound impact on the study of motivation and achievement in academic settings [2]. Bandura emphasized in social cognitive theory the construct of self-efficacy and itsimpact on learning, as this belief in one's own ability influences choice of activitiesand effort [3]. Academic self-efficacy refers to individuals can use their abilities to complete the study, control their own behaviors, and judge their academic achievement [4-6]. Academic self-efficacy was the strongest single predictor of students' academic achievement and performance.

The concept of student engagement is an extension of the concept of engagement and has gained recognition since the 1990s. Pascarella and Terenzini were the first scholars to apply the term engagement to the student learning process [7]. Student engagement is the degree to which students are engaged in learning in the formal education process and refers to the time, effort, and energy they commit to educational learning tasks, such as school-related learning activities and coursework [8]. Student engagement comprises implicit mental state and mode of thinking and explicit behaviors. Mental state includes attitudes toward learning and interactive awareness of learning; mode of thinking includes learning and cognitive strategies; and behavior includes study time and frequency, participation in discussions, and completing assignments[9-12]. We reviewed relevant literature and found that the three dimensions were affected by other factors and affected learning outcomes, both to varying degrees. Therefore, examining these separately in a meta-analysis is more appropriate. However, although disparate investment in these three dimensions exerted different effects, the three dimensions do not operate independently, and a close relationship exists among the three dimensions[11].

\section{METHOD}

This study examined research on academic self-efficacy and student engagement by searching the ERIC, EBSCOHost, PsycINFO, Sciverse Science Direction (SDOL), ProQuest Dissertations \& Theses (PQDT), SpringerLink, JSTOR, Wiley Online Library, Wilson Web. We performed searches using the keywords "academic self-efficacy", "student engagement", "behavioral engagement”, "emotional engagement”, and "cognitive engagement" in the title or abstract fields. The participants of the studies had to be students in elementary school, junior or high school, or college. We found that most studies have used samples of students in the United States. To avoid cultural differences affecting the study results, we 
included only those studies that have focused on American students. Finally, considering when the student engagement concept gained prominence, we limited our searches to articles published between 1990 and 2014. This study included 26 articles on academic self-efficacy and student engagement. The data were transformed by Comprehensive Meta-analysis (CMA). The proposed models include fixed, random, and mixed effects addressed as follows:

\section{A. Fixed Effects Model}

To determine moderators that may have caused heterogeneity in the study results, an analysis and exploration of the moderators should be included. One-way ANOVA was used to determine the $\mathrm{Q}$ value in the homogeneity tests and to determine whether to accept or reject the fit of the fixed effects model [13]. An explanation of equations used in combining effect sizes and homogeneity tests is as follows [14]:

1. Use (1) to calculate Fisher's $\mathrm{Zr}$ value, using the original $r$ value provided by studies or a converted $r$ value;

2. Use (2) to calculate the variation in Fisher's Zr value;

3. Use (3) to determine the weighted average Fisher's $\overline{z_{r}}$ value after combining effect sizes;

4. Use (4) to determine the variation in weighted average Fisher's $\overline{\overline{z_{r}}}$ value; and

5. Use (5) to calculate the Qfix value of the homogeneity test. Compare the Qfix value with the p value. Determine whether $\mathrm{p}$ was significant. Use the significance of $\mathrm{p}$ to determine whether the effect size was homogeneous.

$$
\begin{aligned}
& \left.Z_{r t}=\frac{1}{2} \ln \mid \frac{1+r}{1-r}\right\rfloor \\
& v_{t}=\frac{1}{n_{l}-3}=\frac{1}{w_{i}}\left(n_{i}\right. \text { is the sample }
\end{aligned}
$$

size of the $i^{\text {th }}$ study)

$$
\overline{z_{r}}=\frac{\sum_{i=1}^{k} w_{i} z_{r i}}{\sum_{i=1}^{k} w_{i}}(k \text { is the sum of }
$$

combined effect sizes)

$$
\begin{aligned}
& v_{.}=\frac{1}{\sum_{t=1}^{k} w_{t}} \\
& Q=\sum_{t=1}^{k} w_{t}\left(z_{r t}-\overline{z_{r}}\right)^{2}
\end{aligned}
$$

In this study, if $\mathrm{p}$ was higher than .05, then the study result was deemed homogeneous, and the fixed effect calculated using CMA was accepted. If $\mathrm{p}$ was less than .05, then the study result was deemed heterogeneous and required moderator analysis. However, the $\mathrm{Q}$ value determines only whether homogeneity exists, but I2 can be used to indicate the degree of variation in effect size. The standards for I2 are as follows: $25 \%$ represents low heterogeneity, 50\% represents moderate heterogeneity, and 75\% represents high heterogeneity [15]. When heterogeneity is high, the fixed effects model is not a good fit for the data [16].
If the fixed effects model was used, the $r$ value could be found given the weighted average Fisher's $\overline{z_{r}}$ value by consulting a reference table or by reverse engineering using (1). The calculated $r$ value represented the combined effect size and was used in significance testing. If the p value was less than .05, then a correlation existed between the research variables. Equation (6) can be used to calculate the 95\% confidence interval of the weighted average combined effect size $r$.

$$
\overline{z_{r}} \pm 1.96 \sqrt{v}
$$

\section{B. Random Effects Model}

If the random effects model was used, then the variation of weighted average Fisher's $\overline{z_{r}}$ value was calculated using (7). In (3) and (5), which are used to calculate the weighted average Fisher's $\overline{z_{r}}$ value and Q value, respectively, $w_{t}^{*}$ is used instead of $w_{i}$. To calculate the $95 \%$ confidence interval, ${ }^{v^{*}}$, is used instead of $v_{\text {. . }}$

$$
v^{*}=\sum_{i=1}^{k} w_{t}^{*}=\sum_{i=1}^{k} \frac{1}{v_{i}+t^{2}}
$$

where

$$
\imath^{2}=\left[\begin{array}{cc}
\frac{Q_{\mathrm{flx}}-(k-1)}{\sum_{l=1}^{k} w_{i}-\sum_{i=1}^{k} w_{i}^{2} / \sum_{i=1}^{k} w_{l}} & \text { if } Q_{\mathrm{flx}} \geq k-1 \\
0 & \text { if } Q_{\mathrm{flx}}<k-1
\end{array}\right]
$$

The random effects model was used when the effect size of a study was heterogeneous and required an exploration of relevant moderators. All characteristic variables of the sample in this study were categorical variables; therefore, categorical variables were used in the discussion of moderators. First, using a method similar to one-way ANOVA, we separated the Qfix variable in the homogeneity test into $\mathrm{QB}$, representing the between-group variation, and QW, representing the residual variation. If the results showed that in-group variation was homogeneous but between-group variation was heterogeneous, then this categorical variable had a moderating effect on the research variables. This is one reason that the Qfix variable in the homogeneity test is the determinant of heterogeneity.

\section{Mixed Effects Model}

If QW and QB both reached the significance level of .05, then whether this category of variables contains moderators cannot be determined. In these instances, we employed the mixed effects model. The mixed effects model considers variability in study results produced by moderators. The mixed effects model includes a random variation in addition to sampling error [13]. In addition, effect size was defined according to the $r$ value standards proposed by Cohen [17], where $r=.1$ is a small effect, $r=.3$ is a medium effect, and $r$ $=.5$ is a large effect.

\section{RESULTS}

Table 1 presents the meta-analysis results of the effect of the academic self-efficacy on three dimensions of student 
engagement. All of the Qfix values of academic self-efficacy, representing each dimension's effect size onbehavioral engagement, emotional engagement, and cognitive engagement, reached significance levels of .001, indicating that the variation was much larger than the sampling error. The effect sizes were not homogenous, and I2 values showed high heterogeneity. The CMA of the correlation between the academic self-efficacy and three dimensions of student engagement revealed moderate correlations when the fixed effects model and random effect model was used. In addition, the fail-safe numbers $(\mathrm{p}<.05)$ of academic self-efficacy and behavioral engagement, emotional engagement, and cognitive engagement were 12,344, 1,406, and 1,239 , respectively, which were all significantly higher than the tolerance levels of 130, 70, and 75, respectively. This result indicated a high reliability and that a high number of studies without significant results must be included to overturn the results of the meta-analysis; therefore, studies not included did not affect the results of the meta-analysis.

TABLE I. RESULTSOFTHE EFFECTSOFACADEMICSELF-EFFICACYON STUDENT ENGAGEMENT

\begin{tabular}{|c|c|c|c|c|c|c|c|c|}
\hline \multirow{2}{*}{$\begin{array}{c}\text { Student } \\
\text { engagement }\end{array}$} & \multirow{2}{*}{$\begin{array}{c}\text { No. of } \\
\text { effect } \\
\text { size }\end{array}$} & \multirow[t]{2}{*}{ Model } & \multirow{2}{*}{$\begin{array}{l}\text { Average of } \\
\text { effect size }\end{array}$} & \multicolumn{2}{|c|}{ 95\% confident interval } & \multirow{2}{*}{$Q_{f x x}$ (df) } & \multirow[t]{2}{*}{$I^{2}$} & \multirow{2}{*}{$\begin{array}{c}\text { Fail-safe } \\
\text { Number } \\
\quad(.05)\end{array}$} \\
\hline & & & & Low & Up & & & \\
\hline \multirow[t]{2}{*}{ Behavoral } & \multirow[t]{2}{*}{24} & Fixed effect & $.425^{* * * *}$ & .415 & .434 & $561.3588_{(23)^{* * * *}}$ & 95.903 & 12,344 \\
\hline & & Random effect & $.343^{* * * *}$ & .277 & .406 & & & \\
\hline \multirow[t]{2}{*}{ Emotional } & \multirow[t]{2}{*}{12} & Fixed effect & $.382^{* * * *}$ & .353 & .410 & $137.037_{(11)^{* * *}}$ & 91.973 & 1,406 \\
\hline & & Random effect & $.367^{* * * *}$ & .254 & .471 & & & \\
\hline \multirow[t]{2}{*}{ Cognitive } & \multirow[t]{2}{*}{13} & Fixed effect & $.337^{* * * *}$ & .307 & .366 & $91.906_{(12)^{* * *}}$ & 86.943 & 1,239 \\
\hline & & Random effect & $.337^{* * * *}$ & .248 & .420 & & & \\
\hline
\end{tabular}

The fixed effects model homogeneity test was performed to analyze the three levels of education moderators: higher education, secondary education, and primary education. Table 2 shows that the Qfix values of most of the moderators achieved significant levels of .001. The residual variation (QW) and the variation of the education level variable $(\mathrm{QB})$ reached statistical significance, indicating that a variability caused by random variation may still exist in the three dimensions of student engagement. Thus, the mixed effects model, instead of the fixed effects model, should be adopted to fit the data.
Table 2 shows the average effect size $r$ of the three dimensions of student engagement moderated by education levels reached statistical significance. A homogeneity test was performed on education levels and the three dimensions of student engagement, and only the QB value of behavioral engagement reached a significance level of .001. Heterogeneity existed in the effect size of each education levels. Thus, the moderating effect of education levels on the correlation between the academic self-efficacy and three dimensions of student engagement affected only the behavioral engagement dimension.

TABLE II. RESULTSOFTHE EFFECTSOFACADEMICSELF-EFFICACYON STUDENT ENGAGEMENT

\begin{tabular}{|c|c|c|c|c|c|c|c|c|}
\hline \multirow{2}{*}{$\begin{array}{c}\text { Student } \\
\text { engagement }\end{array}$} & \multirow{2}{*}{$\begin{array}{l}\text { No. of } \\
\text { effect } \\
\text { size }\end{array}$} & \multirow[t]{2}{*}{ Model } & \multirow{2}{*}{$\begin{array}{l}\text { Average of } \\
\text { effect size }\end{array}$} & \multicolumn{2}{|c|}{ 95\% confident interval } & \multirow{2}{*}{$Q_{f f x}$ (df) } & \multirow[t]{2}{*}{$I^{2}$} & \multirow{2}{*}{$\begin{array}{c}\text { Fail-safe } \\
\text { Number } \\
(.05)\end{array}$} \\
\hline & & & & Low & Up & & & \\
\hline \multirow[t]{2}{*}{ Behavoral } & \multirow[t]{2}{*}{24} & Fixed effect & $.425^{* * * *}$ & .415 & .434 & $561.3588_{(23}{ }^{* * * *}$ & 95.903 & 12,344 \\
\hline & & Random effect & $.343^{* * * * *}$ & .277 & .406 & & & \\
\hline \multirow[t]{2}{*}{ Emotional } & \multirow[t]{2}{*}{12} & Fixed effect & $.382^{* * * *}$ & .353 & .410 & $137.037_{(11){ }^{* * * *}}$ & 91.973 & 1,406 \\
\hline & & Random effect & $.367^{* * *+1}$ & .254 & .471 & & & \\
\hline \multirow[t]{2}{*}{ Cognitive } & \multirow[t]{2}{*}{13} & Fixed effect & $.337^{* * * *}$ & .307 & .366 & $91.906_{(12)}{ }^{* * *}$ & 86.943 & 1,239 \\
\hline & & Random effect & $.337^{* * *}$ & .248 & .420 & & & \\
\hline
\end{tabular}

\section{CONCLUSION}

The results show that academic self-efficacy and student engagement yielded a significant average effect size $r$ and that they were correlated, which was verified using Comprehensive Meta-analysis. Using the random effects model, the correlation between academic self-efficacy and behavioral engagement, emotional engagement, and cognitive engagement were respectively .343 ( $\mathrm{p}<.001), .367(\mathrm{p}<.001)$, and $.337(\mathrm{p}<.001)$, indicating moderate correlations. Therefore, if we enhance students' academic self-efficacy, it will also increase student engagement.

The meta-analysis performed in this study revealed that education levels exerted a moderating effect on only the relationship between academic self-efficacy and behavioral engagement. The effect of secondary education was significantly higher than that of primary education or higher education, indicating that, in secondary schools, high academic self-efficacyamong students result in highbehavioral engagement.

\section{REFERENCES}

[1] A. Wigfield, J. B. Byrnes, andJ. S. Eccles, “Adolescent development”, in Handbook of educational psychology,2nd ed.,P. A. Alexander andP. H.Winne, Eds. Erlbaum, NJ, Mahwah, 2006, pp. 87-113.

[2] A. Bandura, "Self-efficacy: The exercise of control", New York, W. H. Freeman, 1997.

[3] D. H. Schunk, andB. J. Zimmerman,"Competence and control beliefs: Distinguishing the means and ends", in Handbook of educational psychology, 2nd ed., P. A. Alexander and P. H. Winne, Eds. Mahwah, NJ, Lawrence Erlbaum Associates, 2006, pp. 349-367. 
[4] S. M. Elias, andR. J. Loomis, "Using an academic self-efficacy scale to address university major persistence", Journal of College Student Development, vol. 41, no. 4, 2000, pp. 450-450.

[5] J.Gaytan, "Instructional strategies to accommodate a team-teachng approach”, Business Communication Quarterly, vol. 73, no. 1, 2011, pp. 82-87.

[6] S. Mercer, L. M.Nellis, R.Martínez, andM. Kirk, "Supporting the students most in need: Academic self-efficacy and perceived teacher support in relation to within-year academic growth”, Journal of School Psychology, vol. 49, 2011, pp. 323-338.

[7] E. T. Pascarella, and P. T. Terenzini, "How college affects students: A third decade of research”, San Francisco, Jossey-Bass, 2005.

[8] G. D. Kuh, "What student affairs professionals need to know about student engagement”, Journal of College Student Development, vol. 50, no. 6, 2009, pp. 683-706.

[9] J. J.Appleton, S. L. Christenson, D. Kim, andA. L. Reschly, "Measuring cognitive and psychological engagement: Validation of the student engagement instrument”, Journal of School Psychology, vol. 44, no. 5, 2006, pp. 427-445.
[10] E. Chapman, "Alternative approaches to assessing student engagement rates”, Practical Assessment, Research \& Evaluation, vol. 8, no. 13, 2003. http://PAREonline.net/getvn.asp?v=8\&n=13.

[11] J. A. Fredricks, P. C. Blumenfeld, andA. H. Paris, "School engagement Potential of the concept, state of the evidence", Review of Educational Research, vol. 74, no. 1, 2004, pp. 59-109.

[12] J. A.Fredricks, W. McColskey, J. Meli, J.Mordica,B. Montrosse, andK. Mooney, "Measuring student engagement in upper elementary through high school: A description of 21 instruments (REL 2011 No. 098)”, 2011, http://ies.ed.gov/ncee/edlabs/regions/southeast/pdf/REL_2011098.pdf.

[13] M. W. Lipsey, and D. B. Wilson, "Practical meta-analysis", Thousand Oaks, CA, Sage, 2001.

[14] T. Pigott, “Advances in meta-analysis”, New York, Springer, 2012.

[15] J. P. T.Higgins, andS. G. Thompson, “Quantifying heterogeneity in a meta-analysis”, Statistics in Medicine, vol. 21, 2002,pp. 1539-1558.

[16] M. Borenstein, L. V, Hedges, J. P. T. Higgins, and H. R. Rothstein, "Introduction to meta-analysis", Chichester, UK, Wiley,2009.

[17] J. Cohen, "Statistical power analysis for the behavioral sciences”, 2nd ed., New York, Routledge Academic, 1988. 